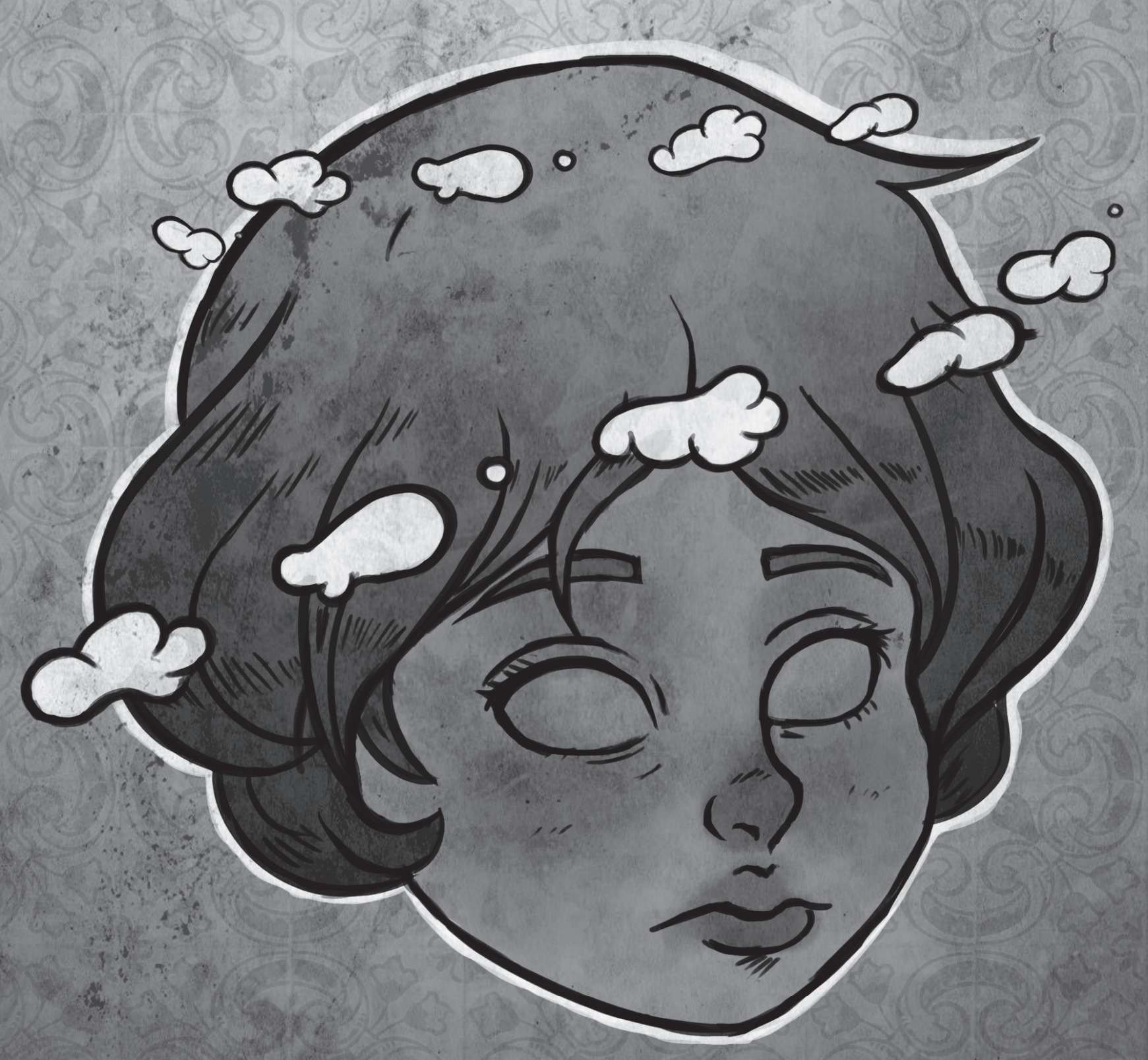

La influencia persuasiva de los estímulos eróticos en la publicidad sobre las tendencias de consumo de los jóvenes (Segunda parte) 


\section{La influencia persuasiva de los estímulos eróticos en la publicidad sobre las tendencias de consumo de los jóvenes (Segunda parte) ${ }^{1}$}

The persuasive influence of erotic stimuli in publicity on youngsters' consumption trends (second part)

\section{Hugo Mastrodoménico Brid (Colombia)}

hugo.mastrodomenico@utadeo.edu.co

Universidad Jorge Tadeo Lozano

Psicólogo de la Universidad Nacional de Colombia

Especialista en Comunicación/Educación de la Universidad

Central. Magíster en Mercadeo Agroindustrial de la Universidad

Jorge Tadeo Lozano.

\section{Resumen}

Con el propósito de obtener evidencia empírica sobre el posible impacto persuasivo de ciertas técnicas empleadas y debatidas en el mundo de la publicidad, se compararon las respuestas de 430 estudiantes universitarios de cinco instituciones quienes fueron expuestos, en un diseño experimental intragrupos, ante pares de piezas publicitarias similares excepto por la presencia o ausencia de estímulos eróticos, con contenido simbólico inconsciente de tipo fálico, vaginal, coital, oral y eyaculatorio, que presentaban o no estímulos subliminales. Se encontró que, en términos generales, la presencia de los estímulos eróticos y de los contenidos simbólicos inconscientes sí aumenta la disposición de adquirir los productos anunciados y la preferencia por el anuncio, sin embargo estos producen un mayor rechazo moralista. Lo contrario ocurrió cuando los contenidos eróticos eran extremos y reconocidos como

tales tales. Estos resultados confirman, por un lado, los argumentos de algunos críticos que denuncian la actividad publicitaria; y por otro, los que apoyan la justificación de algunos publicistas al emplear estas técnicas por su efectividad.

\section{Abstract}

The answers provided by 430 students from different institutions were compared in order to obtain empirical evidence on the possible persuasive impact of certain techniques commonly used and argued in the realm of publicity. The students from 5 different institutions were exposed, in an experimental group design, to similar pairs of pieces of advertisement that only differed from each other in the presence or absence of erotic stimuli with unconscious symbolic content of the phallic, vaginal,

\section{Resumo}

Com o propósito de obter evidência empírica sobre o possível impacto persuasivo de certas técnicas empregadas e debatidas no mundo da publicidade, se compararam as respostas de 430 estudantes universitários de cinco instituições quem foram expostos, em um desenho experimental intragrupos, perante pares de peças publicitárias similares exceto pela presencia ou ausência de estímulos eróticos, com conteúdo simbólico inconsciente de tipo fálico, vaginal, do coito, oral e ejaculatório, que apresentavam ou não estímulos subliminais.

1 Este texto es la segunda parte de La influencia persuasiva de los estímulos eróticos en la publicidad sobre las tendencias de consumo de los jóvenes.

(Segunda parte), publicado en Panorama No. 11, 2011.

Primera parte, publicado en Revista Panorama, No 9, 2011. 
coital, oral and ejaculatory kind, containing or not subliminal stimuli.

It was found that the presence of erotic stimuli and unconscious symbolic content does increase the inclination to acquire the products being advertised and the preference for the advertisement. The latter producing a greater moral rejection, however. The opposite happened when the erotic contents were extreme and identified as such. These results confirm, on the one hand, some critics' claims on publicity practices; and on the other, those made by some to justify the use of these techniques by publicists because of their effectiveness.

Key words: publicity, erotic stimuli, consumption trends, youngsters.

Palabras clave: Publicidad, estímulos eróticos, tendencias de consumo, jóvenes
Encontrou-se que, em termos gerais, a presença dos estímulos eróticos e dos conteúdos simbólicos inconscientes se aumenta a disposição de adquirir os produtos anunciados e a preferência pelo anuncio, embora estes produzam um maior rejeito moralista. O contrário ocorreu quando os conteúdos eróticos eram extremos e reconhecidos como tais. Estes resultados confirmam, por um lado, os argumentos de alguns críticos que denunciam a atividade publicitária; e por outro, os que apoiam a justificação de alguns publicitários ao empregar estas técnicas por sua efetividade.

Palavras chave: Publicidade, estímulos eróticos, tendências de consumo, jovens.

\section{Cita recomendada}

Mastrodoménico, H. (2012). La influencia persuasiva de los estímulos eróticos en la publicidad sobre las tendencias de consumo de los jóvenes. Panorama, 6(11), 111-128. 
El arte de la persuasión es el eje fundamental de las relaciones humanas propias de la convivencia civilizada, en contraposición a la intimidación y el uso de la fuerza, propias de la barbarie.

\section{METODOLOGÍA}

\section{Técnica de Investigación}

\section{Experimento}

Los sujetos participantes fueron expuestos a una serie de piezas publicitarias de tipo visual, y ante ellas expresaron sus reacciones en un cuestionario que fue preparado con anterioridad y les fue entregado. Las piezas, las marcas, los logos y los textos fueron elaborados expresamente para los objetivos del proyecto. El umbral de decisión fue de 0,05 .

\section{Diseño}

Con el fin de responder a 18 de las hipótesis planteadas en este proyecto, y partiendo de los desarroIlos conceptuales para la investigación en el campo de las ciencias sociales de autores como Donald Campbell y Julian Stanley (1970) y especialmente de McGuigan (1984), se eligió el “diseño intragrupos”, por ser la técnica más adecuada para dar cuenta de la complejidad de la problemática abordada.

En este tipo de diseño, se compararon las respuestas dadas por un mismo sujeto ante dos condiciones experimentales diferentes, es decir, ante los valores positivo y negativo de la variable independiente, que en este caso son la presencia y ausencia de símbolos eróticos en piezas publicitarias que, por lo demás, son idénticas. Las respuestas de los sujetos fueron comparadas como funciones de los tratamientos experimentales diferentes.

Para dar respuesta a otras siete de las hipótesis, se hizo un análisis de contenido de las respuestas verbales del tipo asociación libre ante la indicación dada a los sujetos de escribir la primera palabra que se les ocurriera al contemplar las imágenes. En este caso, el diseño también puede ser considerado experimental intragrupos, pero los resultados, si bien se presentan en términos numéricos, no permiten establecer el nivel de significación ni la probabilidad de error. La aceptación o no de las hipótesis se hizo dependiendo de cuál pieza publicitaria obtenía el mayor número de comentarios de cierto tipo.

Para dar respuesta a las otras cinco hipótesis, el diseño experimental no se aplicó. En estos casos se trata de hacer una observación sistemática que entra en la categoría de los diseños cuasi experimentales donde los sujetos son agrupados sólo por poseer una característica específica para después comparar las diferencias en su desempeño ante una misma condición. Por ello en este caso, se observaron las respuestas de los sujetos, de diferentes sexos, ante una misma pieza publicitaria.

\section{Población}


Estudiantes universitarios a nivel de pregrado de la ciudad de Bogotá.

\section{Muestra}

Los 430 sujetos que participaron en esta investigación son estudiantes de pregrado de las siguientes instituciones: Universidad Santo Tomás, Universidad Nacional, Universidad Politécnico Grancolombiano, Universidad Cooperativa y Universidad del Rosario (todas instituciones de la ciudad de Bogotá). Dichos estudiantes cursan diversos tipos de programas académicos y 30 de ellos son quienes participan en la muestra. La prueba fue realizada en 22 aulas de clase.

La muestra está conformada por los estudiantes de dichas instituciones cuyos profesores fueron invitados por conveniencia situacional a colaborar y permitieron la ejecución de la prueba; se trata de estudiantes que aceptaron prestar su colaboración (después de ser incentivados) y que además completaron el cuadernillo de respuestas en más de un 90\%. Finalmente, la muestra quedó conformada por 229 mujeres y 201 hombres. Sus edades fluctúan entre 15 y 33 años. El 90\% de ellos están entre los 17 y los 22 años.

Es necesario aclarar que la presente debe considerarse como una muestra a conveniencia, pues a pesar de su tamaño no puede considerarse representativa de la población universitaria bogotana debido a que no se le dio a cada uno de los integrantes de la población, la misma posibilidad de quedar incluido en la muestra. Esto implica que los resultados de la presente investigación no pueden generalizarse a la población.También es bueno dejar en claro que cuando se llevan a cabo experimentos con seres humanos, la generalización de los resultados sólo puede hacerse cuando al replicar las pruebas, se obtienen resultados similares, o cuando los resultados similares se obtienen en condiciones análogas, pero en circunstancias socioculturales diferentes. Lo recomendable y lo usual en el campo de la experimentación en las ciencias humanas y sociales es la prudencia a la hora de hacer generalizaciones, incluso si se considera que lo mejor es abstenerse de ello (Campbell \& Stanley, 1970).

\section{PRINCIPALES RESULTADOS}

EROTISMO MAYOR vS. EROTISMO MENOR
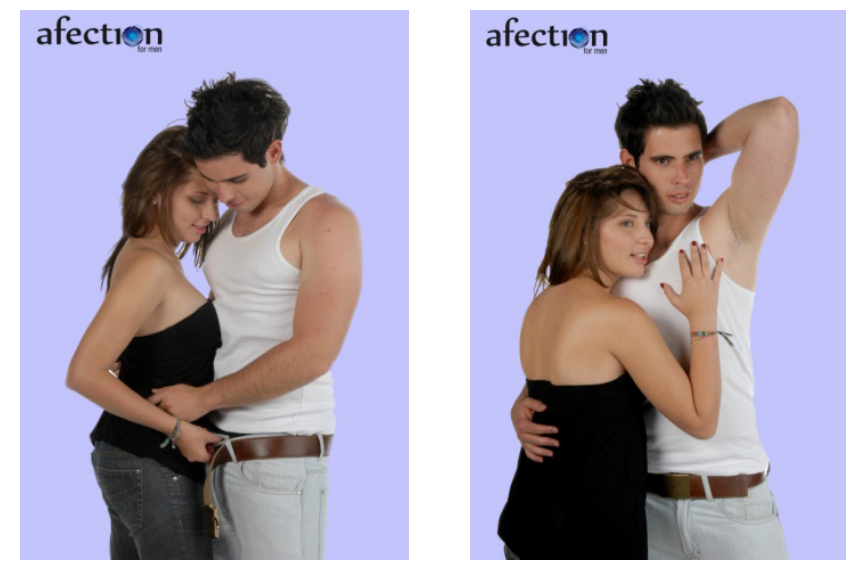


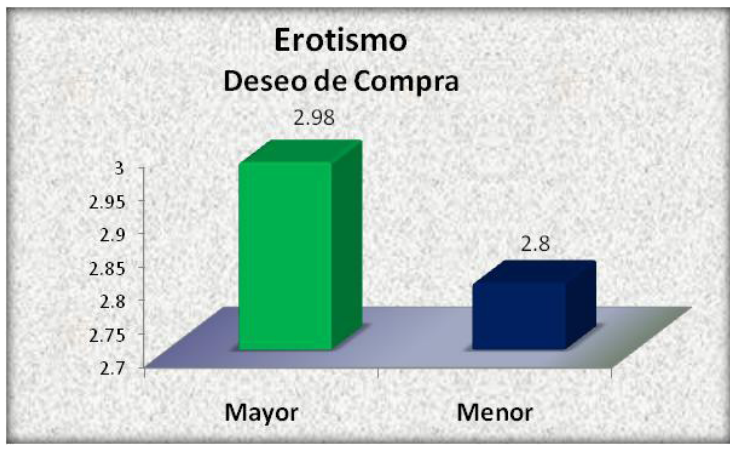

Probabilidad de error: 0,000

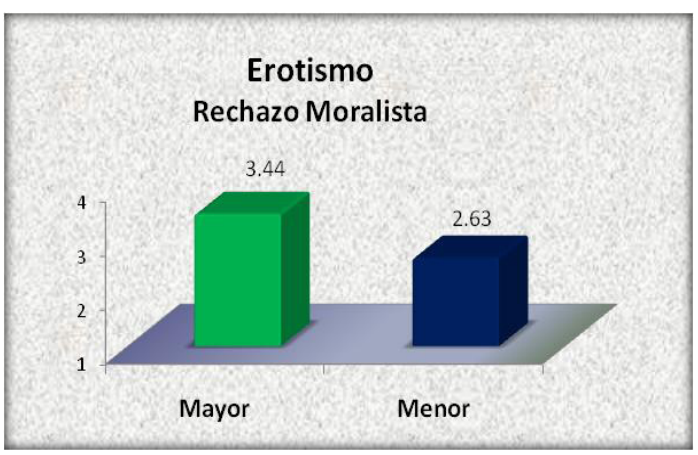

Probabilidad de error: 0,005

Al observar las respuestas de los sujetos ante estas dos piezas publicitarias, se evidencia que si bien el empleo del erotismo despierta inquietud moralista, también produce una mayor intención de compra.

\section{Publicidad escandalosa MAYOR Y MENoR}
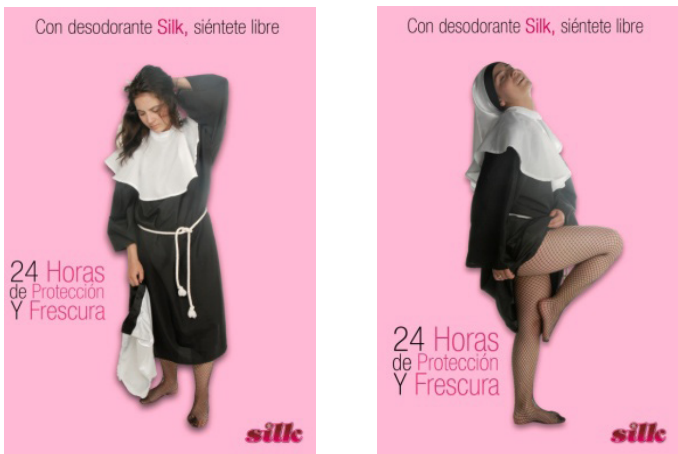

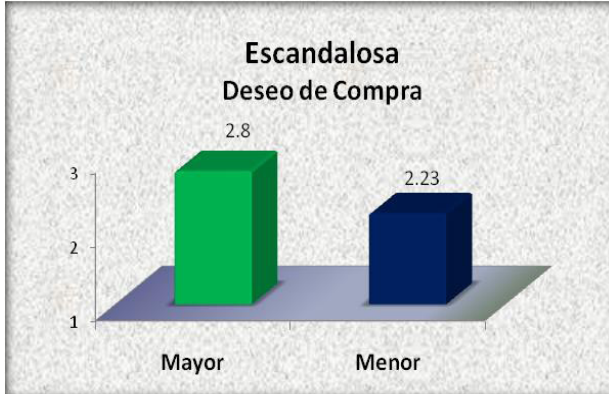

Probabilidad de error: 0,001

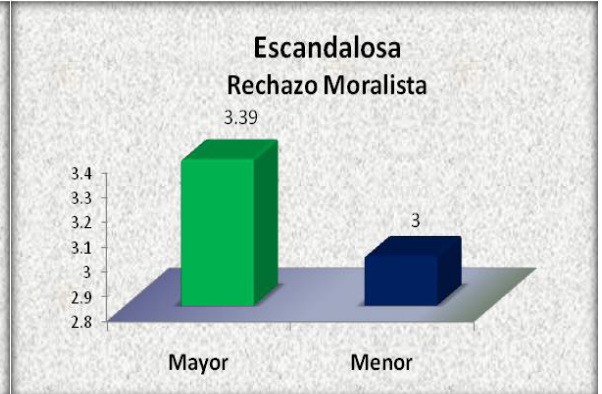

Probabilidad de error: 0,000

Nuevamente, al observar las respuestas de los sujetos ante estas dos piezas, se evidencia que si bien el empleo del erotismo de tipo escandaloso despierta inquietud moralista, también produce una mayor intención de compra. 


\section{Simbolismo FÁLICO EVIDENTE Y NO EVIDENTE}
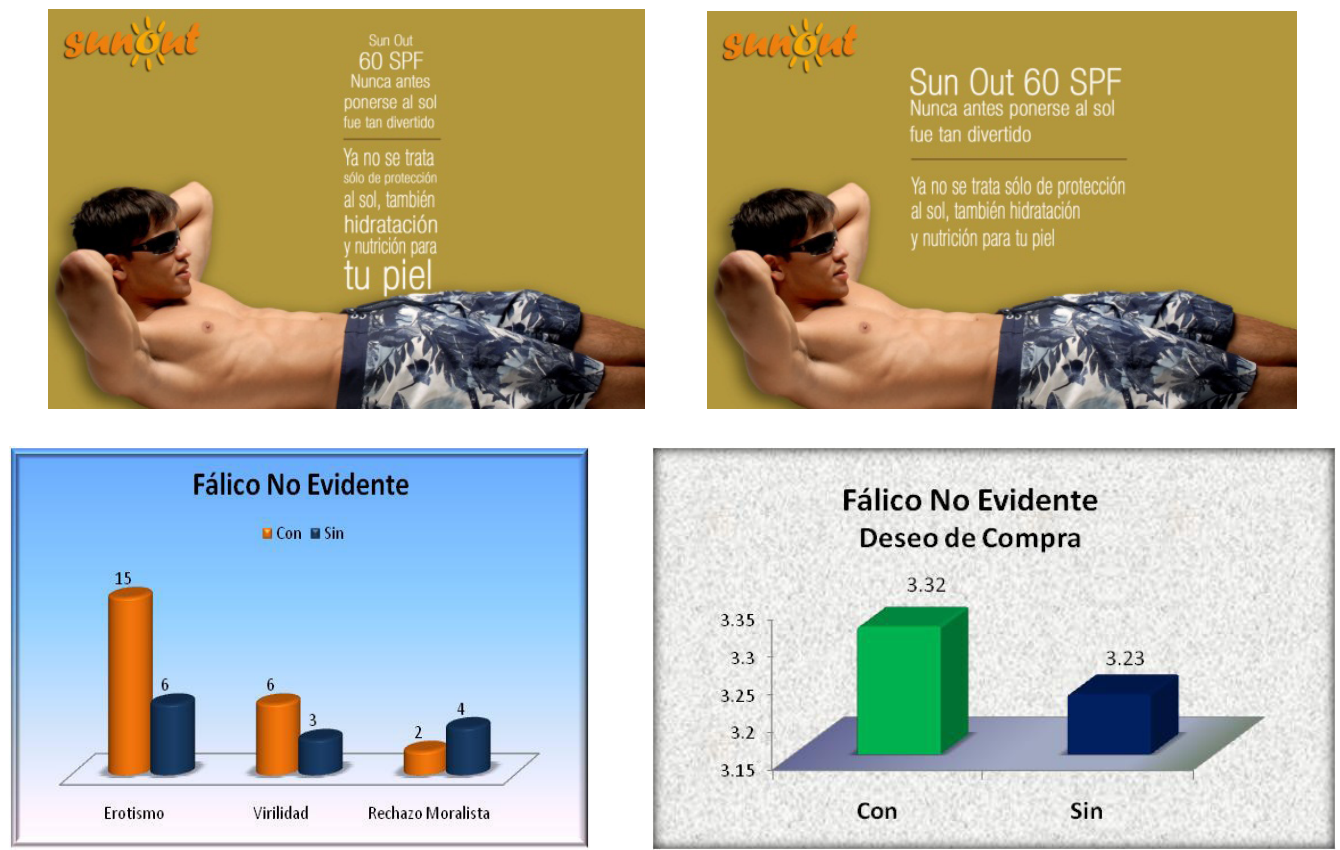

Probabilidad de error: 0,077

\section{Respuestas Verbales asociadas Al tema InVESTIGAdo}

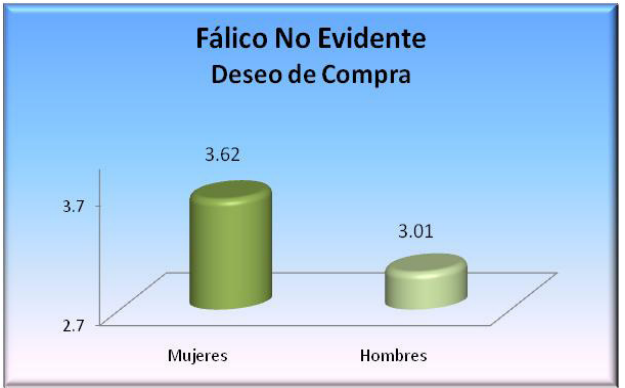

Probabilidad de error: 0,037

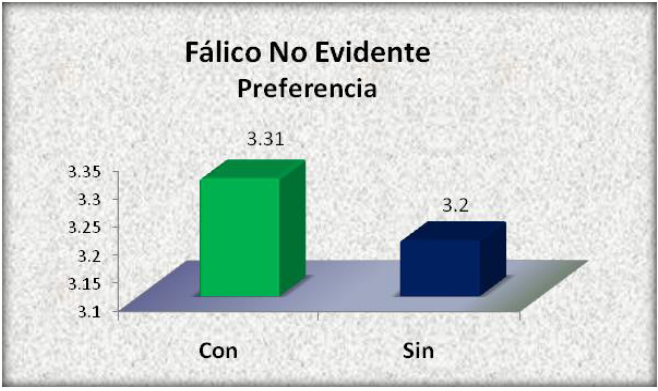

Probabilidad de error: 0,018

Al analizar y comparar las anteriores respuestas, se evidencia que, en general, lo sujetos no fueron conscientes de la estrategia del simbolismo fálico no evidente, porque: 1) la estrategia es eficaz solo si incrementa la intención de compra, 2) aumenta la preferencia por el anuncio y este efecto es marcadamente más efectivo con las mujeres que con los hombres. 


\section{Simbolismo fálico evidente y no evidente}
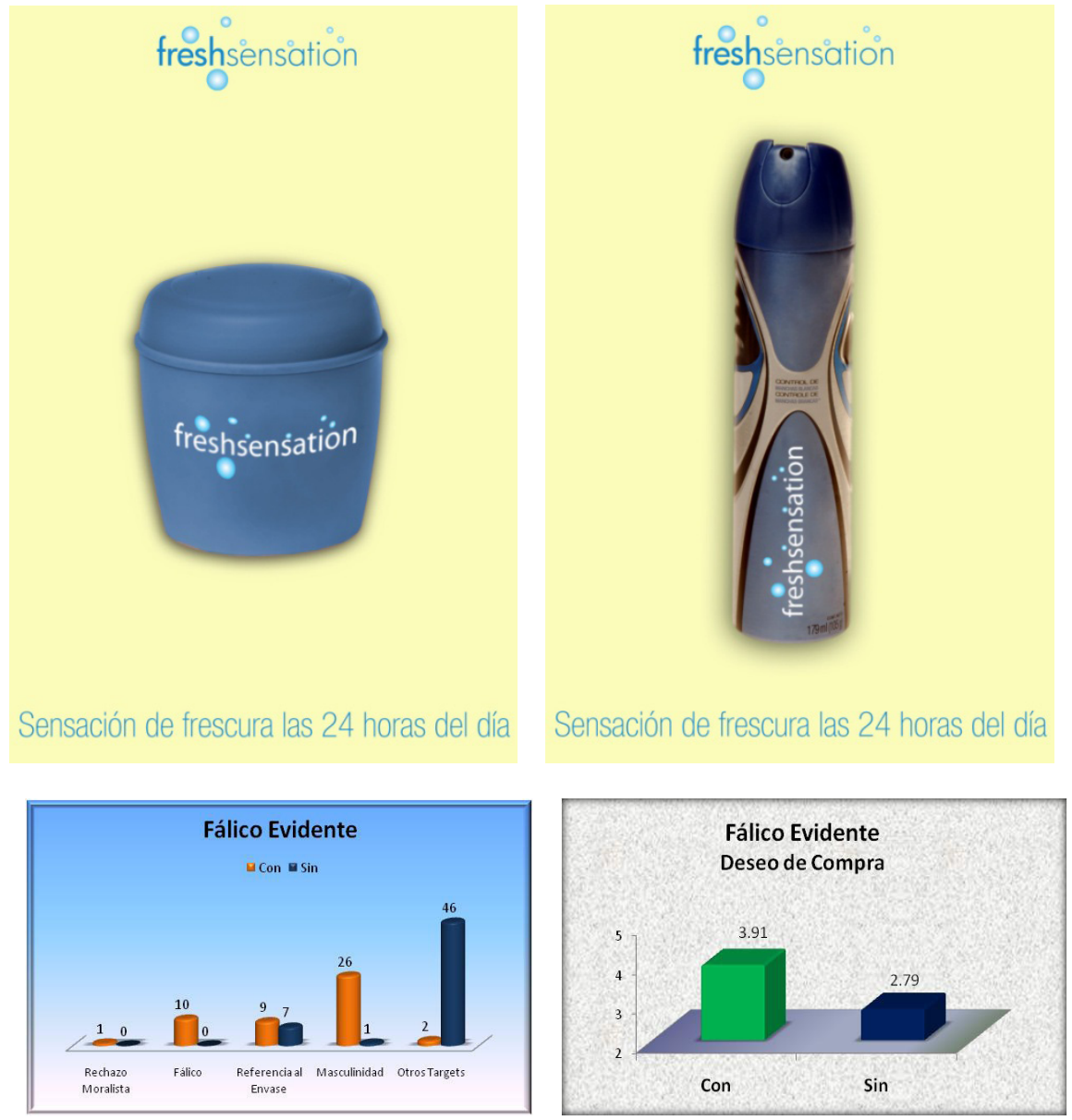

Probabilidad de error: 0,000

\section{Respuestas VERBALES ASOcIADAS AL TEMA INVESTIGAdO}

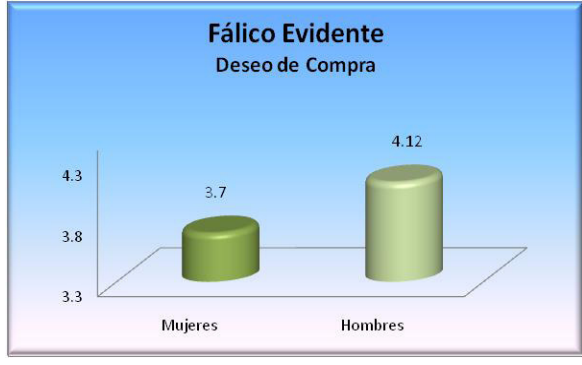

Probabilidad de error: 0,000

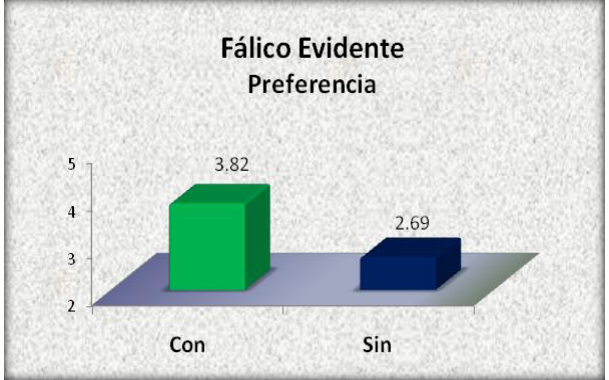

Probabilidad de error: 0,001

$\mathrm{Al}$ analizar y comparar las anteriores respuestas se evidencia que, en general, los sujetos no fueron conscientes de la estrategia del simbolismo fálico evidente, aunque algunos lo asociaron con masculinidad; mientras que el anuncio rival, lo asociaron con personas diferentes a la idea de lo varonil. También se evidenció que la estrategia es 
eficaz porque incrementa la intención de compra y la preferencia por el anuncio; y que, contrariamente a lo ocurrido con el anterior, en este caso el efecto es marcadamente más efectivo con los hombres que con las mujeres.

\section{SimBolismo VAGINAL EVIDENTE Y NO EVIDENTE}

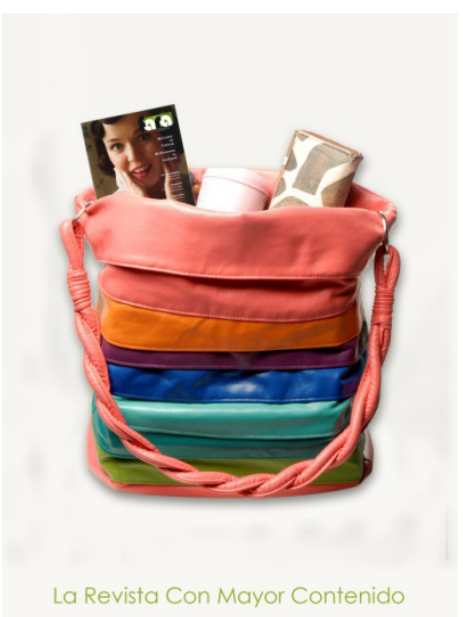

fro

La revista con mayor contenido

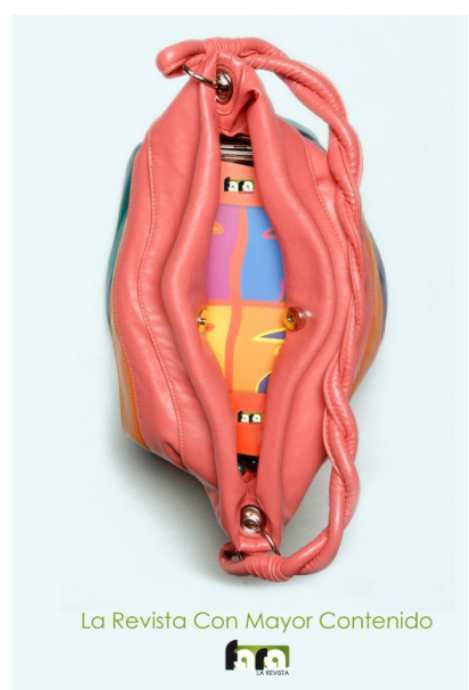

Vaginal evidente

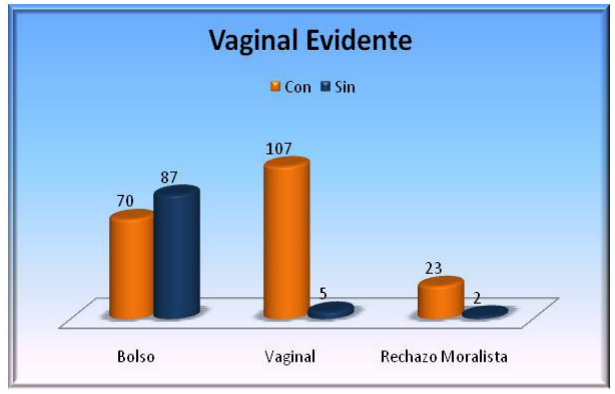

Respuestas Verbales asociadas al tema investigado

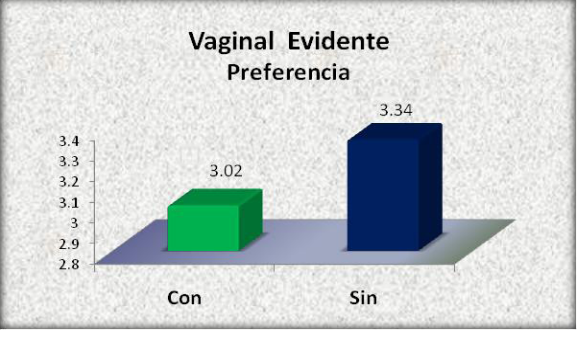

Probabilidad de error: 0,000

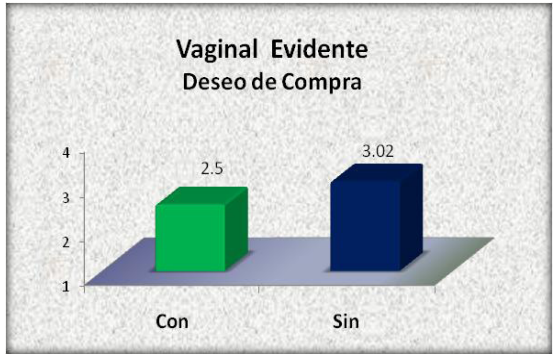

Probabilidad de error: 0,002

Al analizar y comparar las anteriores respuestas, se evidencia que una buena parte de los sujetos fueron plenamente conscientes de la estrategia del simbolismo vaginal. También se evidenció que en estas circunstancias, 
la estrategia disminuye marcadamente la intención de compra y la preferencia por el anuncio. Este resultado estaría marcando los límites de la eficacia de este tipo de técnicas.

\section{Subliminal}

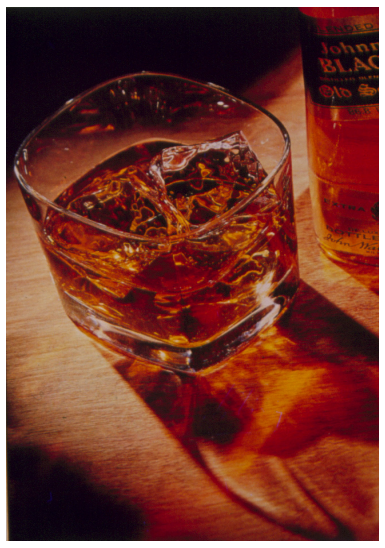

Esta parte de la imagen se extrajo de un anuncio real y se agregó como fotomontaje a uno de los dos anuncios presentados abajo. En la parte inferior de la imagen pueden verse los labios de una vulva expuesta y parte de los muslos separados. Encima de la vulva se aprecia el cuerpo desnudo de una mujer que se encuentra de espalda exponiendo sus glúteos.
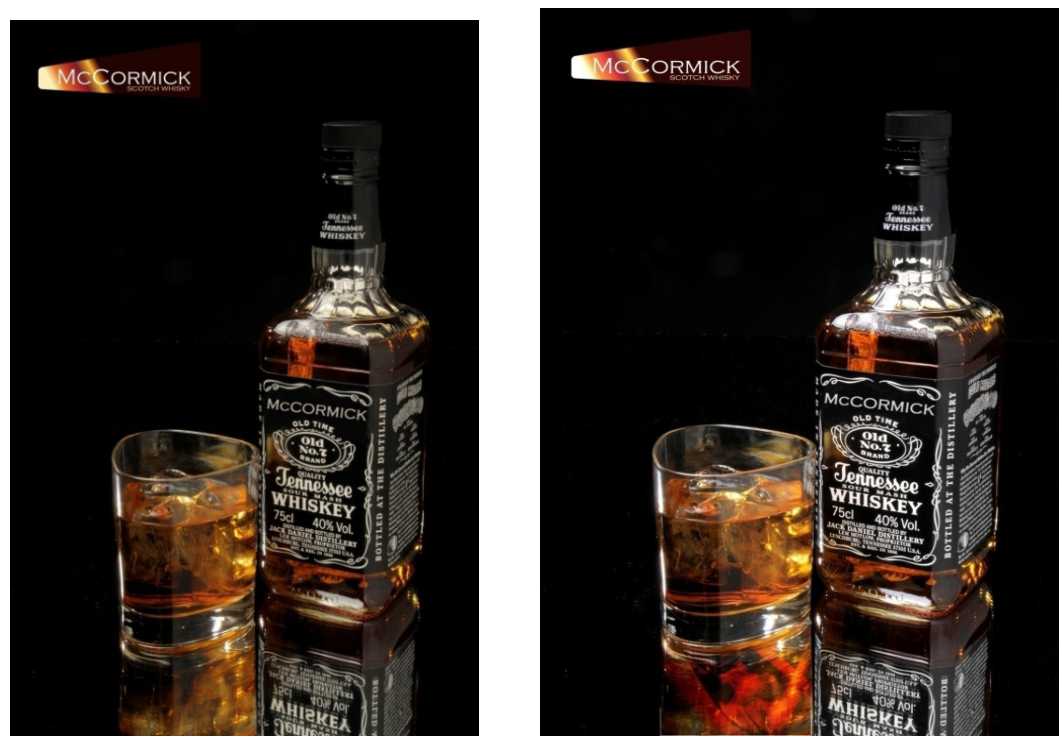


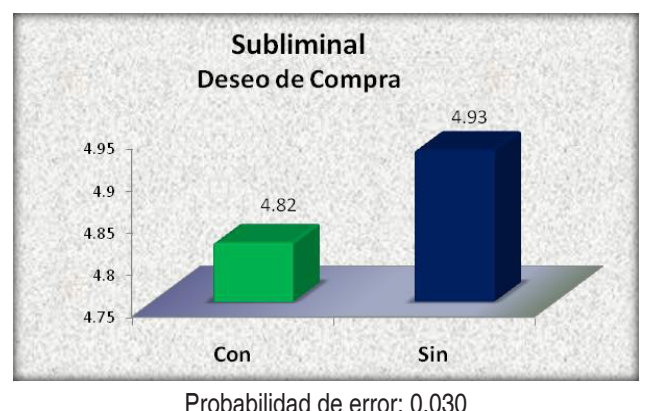

Teniendo en cuenta que en las respuestas verbales no se encontraron alusiones al contenido erótico u oculto, se puede asumir que las respuestas a estos dos anuncios no involucran conciencia del contenido subliminal de uno de ellos. Sorprendentemente, el anuncio que no contiene el elemento subliminal obtiene resultados significativamente superiores en la intención de compra, en comparación con su contraparte. Esto indica que los sujetos sí reaccionaron ante la presencia del contenido subliminal pero no para preferir el producto, sino para rechazarlo. De esta manera se obtiene evidencia empírica de la existencia de defensas inconscientes en la mente humana contra las técnicas de influencia ocultas de la publicidad; y se confirma, aún más, la eficacia de las técnicas de persuasión subliminal y el fenómeno de la percepción subliminal.

\section{CONCLUSIONES}

El resultado de décadas de mucha polémica y poca investigación ha hecho que gran parte de las afirmaciones del psicoanálisis hayan estado en una especie de limbo para la ciencia, pues se trata de afirmaciones que aún están en el terreno de las creencias al no ser validadas o refutadas ni por sus críticos ni por sus defensores. Curiosamente, en los casos donde la investigación sí se ha ocupado de las afirmaciones del psicoanálisis, éste, en términos generales, ha salido bien librado (Garrison \& Loredo, 2002).

La presente investigación no pretende finalizar la polémica epistemológica que por décadas ha enfrentado a los psicólogos; no obstante, se ha llevado a cabo partiendo de la consideración de que sí es posible aportar evidencia empírica que apoye uno de los dos puntos contrapuestos en la pregunta inicial. Así mismo se consideró inicialmente que, con todas las dificultades, sigue siendo posible emplear el método experimental y las técnicas cuantitativas en algunos campos de las ciencias humanas y sociales; y, adicionalmente, también es posible propiciar un nuevo punto de partida en el campo del marketing y la publicidad para refrescar el debate acerca de la eficacia y la ética al emplear los estímulos eróticos en los mensajes persuasivos con fines comerciales.

Al hacer una revisión de las respuestas a las hipótesis planteadas en este estudio, se encuentra que casi todas ellas se cumplieron y, en su gran mayoría, lo hicieron de manera significativa o muy significativa. Puesto que las hipótesis fueron planteadas afirmando que los estímulos eróticos sí son influyentes persuasivamente sobre el receptor, la primera conclusión es que, en términos generales, la inclusión de estímulos eróticos en la publicidad, sí incrementa las probabilidades de compra del producto anunciado. 
Para confirmar la anterior aseveración, conviene tener en cuenta los resultados que se obtuvieron al comparar las piezas publicitarias carentes de estímulo erótico, con las que tenían el estímulo erótico, el fálico evidente, el fálico no evidente, el oral, el coital, el eyaculatorio e incluso el estímulo escandaloso que se califica como tal por su contenido erótico. Estas últimas piezas descritas, aventajaron a su contraparte tanto desde el punto de vista de una mayor disposición a comprar el producto por parte de los sujetos investigados, como por su preferencia por el anuncio como tal.

Desde la perspectiva intrapsíquica, estos hallazgos estarían apoyando la afirmación psicoanalítica freudiana que considera al "ello" como una fuerza energética muy poderosa que incide en las decisiones de las personas consciente o inconscientemente. En este sentido, el principio del placer o, si se quiere, la tendencia hedonista de la naturaleza, debe ser siempre tenida en cuenta como un motivo poderoso que, en muchos casos, termina predominando sobre los frenos super yóicos que se le oponen.

Por supuesto, a la luz de los resultados del presente estudio, el hallazgo tiene sus matices. En el caso de las piezas que exhibían los elementos mayormente escandalosos y los mayormente eróticos, además de una mayor disponibilidad de compra, también se obtuvieron mayores rechazos moralistas. Estos resultados, aparentemente contradictorios, nos están poniendo de presente una de las mayores paradojas del comportamiento del consumidor: cuando éste es impactado emocionalmente, incluso en sentido negativo, el anunciante obtiene una ventaja comercial. Desde el punto de vista del anunciante, el cual está, fundamentalmente, interesado en incrementar las ventas, las estrategias atrevidas tienen un costo; pues despiertan muchas críticas, sin embargo el resultado del balance final de pérdidas y ganancias termina siendo favorable.

Todos los hallazgos hasta aquí expuestos, les dan la razón a los profesionales de la publicidad y a los analistas de la función social de esta disciplina, bien sean defensores o críticos; ya que los defensores consideran que la estrategia de los estímulos eróticos es efectiva en términos comerciales (Key, 1987; Mucchielli, 1977; Packard, 1973). De igual manera, los mismos hallazgos relativizan las afirmaciones de quienes consideran que la estrategia no es efectiva (Garrison \& Loredo, 2002). Puesto que los hallazgos sobre la no eficacia de la estrategia fueron obtenidos en otro contexto social y cultural, específicamente en Estados Unidos, donde es lícito suponer que la eficacia de la estrategia está asociada a ciertas características sociales y culturales como las que se encuentran en el medio universitario bogotano.

Otra de las excepciones a la tendencia general, que nos muestra que los estímulos eróticos sí resultan efectivos, se puede observar en la pieza que contenía el estímulo vaginal evidente; en ella los resultados fueron totalmente opuestos a lo predicho (obsérvese el apartado de resultados); pues en este caso los resultados muestran que la pieza que no contenía el estímulo erótico fue elegida de manera muy significativa para la compra y por preferencia, en comparación con su contraparte. 
El anterior resultado da cuenta de las limitaciones que tuvo la estrategia en la utilización de los estímulos eróticos. Los resultados indican que cuando tal estrategia es muy atrevida, al punto de resultar evidente para el receptor, logra reconocerla y recordarla, pero al mismo tiempo expresa su rechazo por ella; y de ésta manera la disposición a comprar el producto y el agrado por el anuncio disminuyen muy significativamente. También se evidenció que esta tendencia es mayor en el caso de los sujetos de sexo femenino.

En términos psicoanalíticos, el hallazgo ya descrito, en su relación con los demás obtenidos en la investigación, puede interpretarse como una situación intrapsíquica donde las tendencias del "super yó" terminan predominando sobre las del "ello", determinando así una respuesta de alejamiento con respecto al objeto. En estos casos, la restricción que se impone a la invasión de contenidos hedonistas en la mente superan ampliamente a los motivos para hacerlo, lo cual se puede interpretar como una expresión conductual de rechazo moralista que, por supuesto, resulta contrario a los intereses del persuasor. La conclusión es que los contenidos eróticos en la publicidad no deben alcanzar un nivel demasiado ofensivo para el receptor.

Para el caso de la pieza publicitaria que contenía el estímulo subliminal, los resultados también contradijeron lo supuesto en las hipótesis, lo cual fue muy significativo en el caso de la disposición de compra. Puesto que la diferencia en las respuestas ante las dos piezas comparadas, la que tenía el estímulo subliminal y la que no, fueron muy significativas, el resultado indica que el elemento subliminal de todas maneras fue captado y produjo efectos en el comportamiento de los sujetos, sólo que el efecto resultó contrario al esperado.En términos del debate teórico en el campo de la psicología, el anterior hallazgo se suma a otros muchos que indican que los estímulos subliminales sí ingresan al espacio psíquico de las personas, pero su capacidad de influir sobre la conducta en el sentido esperado por el emisor del mensaje, es muy reducida y circunscrita a condiciones muy específicas pues no siempre implican que el receptor realice actos contrarios a sus creencias e intenciones conscientes.

El hallazgo de este proyecto, y de otros proyectos, parece estar indicando que la mayoría de estudios sobre los mensajes subliminales se concentran en observar si el sujeto responde en el sentido esperado por el emisor. En algunos casos se encontró que si se puede encontrar una respuesta leve en tal sentido por parte del receptor. En los estudios como el actual, en los que se les ha dado a los sujetos la oportunidad de expresar la respuesta contraria, se encuentran respuestas con diferencias mucho más marcadas ante las piezas con presencia que con las piezas carentes ausencia del elemento subliminal.

La implicación, en términos teórico-intrapsíquicos, (tendencia de los sujetos a responder de manera diferente cuando se encuentran ante elementos subliminales, y a hacerlo expresando rechazo), consiste en que se ha encontrado apoyo para los autores que enfatizan la importancia de las defensas de los receptores ante los intentos persuasivos. Algunos autores denominan a estas defensas contrasugestión o facultad crítica. De hecho, prácticamente todos los autores reconocen su existencia, pero difieren en la fortaleza que le atribuyen. Pues bien, los resultados de esta investigación apoyan una idea aún más radical: los receptores de mensajes persuasivos no sólo pueden rehusar hacer lo que pide el persuasor y evaluar negativamente el mensaje y la propuesta, sino que también pueden hacerlo inconscientemente. 
Especulando un poco, respecto a este proceso defensivo inconsciente, podría decirse que un individuo al no ser consciente de que está viendo una escena erótica fuerte, (y que por lo demás es muy difícil de ver incluso cuando alguien la está mostrando), una parte de su sistema intrapsíquico "sabe" que tal elemento está allí, "comprende" la intención persuasiva del emisor y "resuelve" expresar su rechazo a tal práctica, negándose a hacer lo que le pide la parte evidente del mensaje. De resultar cierta tal suposición, estaríamos hablando de procesos inconscientes de tipo emocional que afectarían el desempeño intelectual del individuo en circunstancias como la toma de decisiones.

En lo que tiene que ver con la vieja discusión acerca de la existencia del inconsciente, discusión que ya deja de tener sentido por la abrumadora evidencia no sólo psicológica sino fisiológica en sentido afirmativo, los resultados del presente estudio indican claramente la participación en la toma de decisiones de procesos de los que el sujeto no se da cuenta. Tal cosa se evidencia en muchas de las respuestas diferentes emitidas por los sujetos ante piezas en las que no notaban diferencia alguna e incluso mencionaban ya haberlas evaluado. También es especialmente notoria en los casos donde las dos piezas publicitarias resultaban muy similares y se necesitaba una observación muy atenta o una indicación señalando la diferencia para que el sujeto fuera consciente de estar evaluando una pieza diferente; esto ocurrió especialmente en las piezas con elementos simbólicos coitales, fálicos no evidentes y, sobre todo, en las que tenían mensajes subliminales.

Otro hallazgo que vale la pena señalar como fruto de este estudio es que se evidenció que en la muestra investigada, las mujeres responden de manera diferente a los hombres. En el grupo femenino fue mayor el rechazo moralista ante los estímulos eróticos y menor correspondiente deseo de compra. Curiosamente, aunque no para el psicoanálisis, las mujeres reaccionaron con un deseo de compra significativamente mayor que los hombres cuando el símbolo fálico no era evidente; el anterior fenómeno se invirtió totalmente cuando el símbolo fálico era evidente. Igualmente, ante el símbolo vaginal evidente, que como ya se indicó fue reconocido inmediatamente en una muy buena proporción, los hombres mostraron una preferencia significativamente mayor por el anuncio, que las mujeres.

Todos los hallazgos anteriormente descritos nos indican una toma de decisiones con predominio en los factores hedonistas, más marcado en los sujetos de sexo masculino. En el caso de los sujetos de sexo femenino, su preferencia, deseo de compra y rechazo moralista son coherentes con un predominio de los factores "super yóicos". Sin embargo, cuando los contenidos simbólicos no son evidentes, la respuesta favorable de las mujeres resultó ser significativamente más alta.

Estos hallazgos confirman los supuestos de Arellano (2002), quien afirma que en los países latinoamericanos, los cambios debido al empoderamiento de la mujer y por ende como consumidora, se encuentran algunos pasos atrás con respecto a sus pares de otros países, pues su apego a los valores tradicionales las lleva, más que a los hombres, a anteponer en sus decisiones conscientes las tendencias moralistas del "super yó" a las hedonistas del "ello". Esta circunstancia las haría más vulnerables a las tácticas persuasivas de tipo erótico que se mantienen en el terreno de lo oculto y lo sutil. 
Con respecto a la discusión de carácter ético, planteada en este estudio, los resultados obtenidos le dan la razón a los críticos de la publicidad, quienes siempre le han atribuido a la publicidad una gran capacidad para influir sobre las personas de manera no muy transparente. Sin embargo los publicistas también reciben respaldo de los resultados aquí obtenidos, pues ellos justifican estas estrategias enfatizando su eficacia, al menos en nuestro contexto social y cultural latinoamericano.

Ante esta situación de eficacia, la alternativa que puede plantear este estudio consiste en que, para alcanzar un mayor grado de ejercicio ciudadano, las técnicas persuasivas que son efectivas deben ser conocidas y discutidas por los ciudadanos corrientes e incluso enseñadas en los primeros años de formación académica de la juventud; de esta manera, en caso de percibir una propuesta de tipo subliminal, ellos podrían aceptarla o no, pues sería fruto de un ejercicio más maduro y más consciente de la libertad de elección del individuo. 


\section{Referencias bibliográficas}

1. Abad Faciolince, H. (20 de Febrero de 2010). Pedradas al hombre adúltero. El Espectador.

2. Arellano, R. (2002). Comportamiento del consumidor. Enfoque América Latina. México: McGraw-Hill.

3. Balle, F. (1991). Comunicación y sociedad. Bogotá: Tercer Mundo.

4. Brenner, C. (1964). Elementos fundamentals de psicoanálisis. Buenos Aires: Editorial Libros Básicos

5. Byerly, H. (1976). Explaining and exploiting placebo effects. Perspectives in biology and medicine, 19, pp.423-236.

6. Campbell, D. \& Stanley, J. (1970). Diseños experimentales y cuasiexperimentales en la investigación social. Buenos Aires: Amorrortu.

7. Dethlefsen, T. \& Dahlke, R. (1998). La enfermedad como camino. Barcelona: Plaza \& Janes.

8. Feldman, R. (1998). Psicología. México: McGraw-Hill.

9. Freud, S. ([1916] 1948). Introducción al psicoanálisis. En S. Freud, Obras Completas (Vol. II). Madrid: Biblioteca Nueva.

10. Garrison, M. \& Loredo, O. (2002). Psicología. México: McGraw-Hill.

11. Inglis, B. (1995). Trance. Historia de los estados especiales de la mente. Girona: Susaeta.

12. Jung, C. \& Wilhelm, R. (1974). El secreto de la flor de oro. Buenos Aires: Paidós.

13. Key, W. (1987). Seducción subliminal. México: Diana.

14. Loudon, D. \& Della Bitta, A. (1995). Comportamiento del consumidor. México: McGraw-Hill.

15. Mann, L. (1973). Elementos de psicología social. México: Limusa.

16. Mastrodoménico, H. (1979). Psicología deportiva: el efecto placebo sobre el rendimiento en un ejercicio de resistencia aeróbica. Tesis de Grado. Bogotá: Universidad Nacional de Colombia.

17. Morris, C. (1987). Psicología. México: Prentice-Hall.

18. Morris, C. \& Maisto, A. (2001). Introducción a la Psicología. México: Prentice-Hall.

19. Mucchielli, R. (1977). Psicología de la publicidad y de la propaganda. Bilbao: Mensajero. 
20. Packard, V. (1973). Las formas ocultas de la propaganda. Buenos Aires: Sudamericana.

21. Pérez, A. (1978). El efecto placebo en psicoterapia. En: A. Pérez, Monografías psicológicas: Psicología clínica. Bogotá: Universidad de los Andes.

22. Piaget, J. (1980). Problemas de psicología genética. Barcelona: Ariel.

23. Shapiro, A. (1971). Placebo effects in medicine, psychotherapy and psychoanalysis. En: Borging \& Garfield, Handbook of psychotherapy and behavior change.

24. Wells, W., Burnet, J. \& Moriarty, S. (2007). Publicidad, principios y prácticas. México: Pearson.

25. Wilhelm, R. (1982). I Ching. El libro de las mutaciones. Barcelona: Edhasa.

\section{Agradecimientos}

A todos los estudiantes universitarios que colaboraron como sujetos de investigación.

Al Doctor Christian Schrader Valencia, Decano del Programa de Publicidad de la UniversidadJorge Tadeo Lozano por su constante apoyo y buenos oficios para adelantar exitosamente este proyecto.

A los profesores Andrés Rodríguez Martínez, José Castillo y Carlos Santacruz por su trabajo en la planeación y realización de las piezas publicitarias necesarias para adelantar el presente proyecto.

A los estudiantes semilleros y asistentes que participaron en todas las fases de desarrollo de este proyecto. 